\title{
The Long Noncoding RNA TUG1 Promotes Laryngeal Cancer Proliferation and Migration
}

\author{
Zhonghua Zhang $^{\mathrm{a}}$ Xuehai Wang ${ }^{\mathrm{b}}$ Shengda Cao ${ }^{\mathrm{a}}$ Xiao Han ${ }^{\mathrm{a}}$ Zhanwang Wang ${ }^{\mathrm{a}}$ \\ Xiaoyan Zhao ${ }^{a}$ Xuejun Liu ${ }^{a}$ Guojun Lic, ${ }^{\mathrm{c}}$ Xinliang Pan ${ }^{\mathrm{a}}$ Dapeng Lei ${ }^{\mathrm{a}}$ \\ aDepartment of Otorhinolaryngology, Qilu Hospital, Shandong University, Key Laboratory of \\ Otolaryngology, NHFPC (Shandong University), Jinan, ${ }^{b}$ Department of Otorhinolaryngology, Weihai \\ Municipal Hospital, Weihai, China, 'Department of Head and Neck Surgery, The University of Texas MD \\ Anderson Cancer Center, Houston, dDepartment of Epidemiology, The University of Texas MD Anderson \\ Cancer Center, Houston, USA
}

\section{Key Words}

Long noncoding RNAs $\bullet$ TUG1 $\bullet$ Laryngeal squamous cell carcinoma $\bullet$ proliferation $\bullet$ metastasis

\begin{abstract}
Background/Aims: Researchers have shown that long noncoding RNAs are closely associated with the pathogenesis of laryngeal squamous cell carcinoma (LSCC). However, the role of the long noncoding RNA taurine-upregulated gene 1 (TUG1) in the pathogenesis of LSCC remains unclear, although it is recognized as an oncogenic regulator for several types of squamous cell carcinoma. Methods: qRT-PCR was performed to measure the expression of TUG1 in LSCC tissues and cell lines. 3-(4,5-dimethyl-2-thiazolyl)-2,5-diphenyl-2-H-tetrazolium bromide (MTT) was used to measure the effect of TUG1 on cell proliferation. Transwell assay and flow cytometry were employed to determine the effect of TUG1 on cell migration and invasion. Western-blot were performed to explore the relation of TUG1 and p53 mRNA. Results: Higher TUG1 expression in LSCC than in paired normal tumor-adjacent tissue specimens $(N=64)$ was observed using quantitative real-time polymerase chain reaction. Also, high TUG1 expression was positively associated with advanced T category, worse lymph node metastasis and late clinical stage. Furthermore, in vitro experiments demonstrated that silencing of TUG1 markedly inhibited proliferation, cell-cycle progression, migration, and invasion of LSCC cells, whereas depletion of TUG1 led to increased apoptosis. Conclusion: These findings demonstrated that upregulated TUG1 expression exerted oncogenic effects by promoting proliferation, migration, and invasion, and inhibiting apoptosis in LSCC cells.
\end{abstract}




\section{Introduction}

Laryngeal squamous cell carcinoma (LSCC) is the most common carcinoma in the head and neck, accounting for about $0.62 \%$ of all human malignancies. In 2015 , the mortality rate for LSCC was $0.52 \%$ in the Chinese population [1]. Thus, intensive research to determine the molecular mechanisms underlying the pathogenesis of LSCC, which would be helpful for ameliorating its diagnosis and treatment, is still needed. Many mediators are involved in the pathogenesis of this malignancy, such as epidermal growth factor receptor [2, 3], cyclooxygenase-2 [4, 5], p53 [6], cyclin D1 [7], and microRNAs [8]. With the development of genome-wide sequencing technologies, a number of long noncoding RNAs (lncRNAs) have emerged as important players in the physiopathology of LSCC, specifically, as potential diagnostic biomarkers or therapeutic targets.

LncRNAs, which are longer than 200 nucleotides and lack protein-coding ability [9, $10]$, are well recognized as important regulators of processes such as gene expression and chromosome modification, by which they exert critical effects on regulation of cell proliferation, differentiation, and chromosome inactivation $[11,12]$. Moreover, an increasing number of lncRNAs are closely associated with the pathogenesis of cancers with altered IncRNA expression, such as breast cancer, lung cancer, pancreatic cancer, hepatocellular carcinoma, and leukemia [13-16].

With the application of genome-wide sequencing analysis, researchers confirmed that the expression of several lncRNAs, such as HOTAIR [17], MALAT-1[18], and H19 [19], is upregulated in LSCC cells. Investigators first identified the lncRNA taurine-upregulated gene 1 (TUG1), a 7.1-kb gene located at chr22q12.2 and consisting of four exons, in a microarray and found that its transcript was upregulated in taurine-treated retinal cells in mice [20]. Recent studies revealed that TUG1 was involved in the development of a variety of cancers, including some squamous cell carcinomas. However, the role of TUG1 in the pathogenesis of LSCC has yet to be explored. Therefore, in the present study, we detected the expression of TUG1 in 64 pairs of LSCC and corresponding adjacent nontumor tissue specimens, and further identified the role of TUG1 in the regulation of LSCC. We discovered that TUG1 was more highly expressed in LSCC specimens than in adjacent nontumor tissue specimens using quantitative real-time polymerase chain reaction (qRT-PCR). Moreover, we found that elevated expression of TUG1 was positively correlated with poor clinicopathological characteristics of LSCC patients. In vitro experiments further suggested that TUG1 is involved in the pathogenesis of LSCC by affecting the proliferation, apoptosis, and invasive ability of LSCC cells.

\section{Materials and Methods}

\section{Patients and specimens}

Tumor and matched adjacent normal tissue specimens were collected from 64 LSCC patients who underwent surgery in the Department of Otolaryngology, Qilu Hospital of Shandong University from July 2015 to December 2016. All of the LSCC cases were pathologically confirmed, and the patients did not receive chemoradiotherapy or biotherapy before surgery. All of the supraglottic LSCC patients underwent elective bilateral neck dissection, and part of the glottic LSCC patients underwent elective neck dissection according to their imaging results. Specimens were placed in liquid nitrogen within $5 \mathrm{~min}$ after resection and then transferred to a $-80^{\circ} \mathrm{C}$ freezer for long-term storage. The patients' clinical information was obtained from their medical records. TNM staging of all tumors was performed in accordance with the standards of the American Joint Committee on Cancer [21]. Written informed consent to participate in the study was obtained from all patients before surgery, and all the procedures were approved by the Ethics Committee of the Qilu Hospital of Shandong University. 


\section{Cellular Physiology Cell Physiol Biochem 2018:49:2511-2520 \begin{tabular}{l|l|l} 
and Biochemistry Published online: 28 September 2018 & $\begin{array}{l}\text { (c) } 2018 \text { The Author(s). Published by S. Karger AG, Basel } \\
\text { www.karger.com/cpb }\end{array}$ \\
\hline
\end{tabular}}

Zhang et al.: The Role of Upregulated TUG1 in LSCC

\section{Cell cultures}

The LSCC cell line human epithelial-2 (Hep-2) was purchased from and authenticated by the Cell Bank of the Chinese Academy of Sciences (Shanghai, People's Republic of China), and maintained in Dulbecco's modified Eagle's medium supplemented with $10 \%$ fetal bovine serum (Gibco, Grand Island, NY) in a humidified atmosphere containing $5 \% \mathrm{CO}_{2}$ at $37^{\circ} \mathrm{C}$.

\section{RNA extraction and $q R T-P C R$}

Total RNA was extracted from LSCC and normal tissue specimens using TRIzol reagent (Takara Bio, Otsu, Japan) following the manufacturer's instructions. RNA (500 ng) from each specimen was subjected to cDNA synthesis using a reverse transcription kit (RR047A; Takara Bio) immediately after its concentration was determined using a NanoDrop ND-1000 spectrophotometer (Thermo Fisher Scientific, Wilmington, DE). qRT-PCR was performed using SYBR Green Real-Time PCR Master Mix (Toyobo, Osaka, Japan) and an ABI 7900HT qRT-PCR system (Applied Biosystems, Foster City, CA). TUG1 and $\beta$-actin were amplified in triplicate at an annealing temperature of $60^{\circ} \mathrm{C}$. The relative expression of TUG1 and p53 was calculated using the $\Delta \Delta \mathrm{Ct}$ method [22], and $\beta$-actin was used as an internal control. Their sequences were as follows: TUG1: forward, 5'-CTGGACCTGGAACCCGAAAG-3'; reverse, 5'-GGTAGTGCTTGCTCAGTCGT-3'; p53: forward, 5'-GCGCACAGAGGAAGAGAATC-3'; reverse, 5'-CAAGGCCTCATTCAGCTCTC-3'; and $\beta$-actin: forward, 5'-CATGTACGTTGCTATCCAGGC-3'; reverse, 5'-CTCCTTAATGTCACGCACGAT-3'.

\section{Transfection}

Well-differentiated Hep- 2 cells were cultured in 24-well plates, and when they reached $50 \%$ confluence, they were transfected with a mixture of TUG1-targeted small interfering RNA (siTUG1; $30 \mathrm{nmol} / \mathrm{l}$, diluted in Dulbecco's modified Eagle's medium) or a scrambled control (negative control small interfering RNA [siRNA]) and Lipofectamine 2000 (Invitrogen, Carlsbad, CA) following the manufacturer's protocol. After 48 $\mathrm{h}$ of incubation, transfected cells were used for further experiments. The siTUG1 sequences were as follows: sense, 5'-GCGAGUCACUCUGUAAU-3'; antisense, 5'-AUUACAGAGUGACUCGC-3' (GenePharma, Shanghai, China). The efficiency of TUG1 silencing was subsequently quantified using qRT-PCR.

\section{Cell proliferation assays}

Proliferation of Hep-2 cells was detected using an MTT assay with a Cell Proliferation Reagent Kit (GeneSeq Inc., Shanghai, China). The transfected cells described above were plated in 96-well plates (2000 cells/well). The absorbance of each well at $570 \mathrm{~nm}$ was measured every $24 \mathrm{~h}$ following the reagent kit's instructions for 5 consecutive days to draw a growth curve. The cells were counted in accordance with the standard growth curve. Cells in triplicate wells were counted for the two treatment groups as stated above.

\section{Transwell assays}

To assess the migration and invasiveness of Hep-2 cells, we used Transwell chambers (Corning Costar, Tewksbury, MA, USA; BD Biosciences, San Jose, CA). Briefly, $3 \times 10^{5}$ cells in serum-free medium were placed in the upper chamber. Dulbecco's modified Eagle's medium (500 $\mu \mathrm{l}$ ) supplemented with $10 \%$ fetal bovine serum was added to the lower chamber. After incubation in a humidified atmosphere containing $5 \% \mathrm{CO}_{2}$ at $37^{\circ} \mathrm{C}$ for $72 \mathrm{~h}$, Giemsa staining of hep- 2 cells that had migrated or invaded into the lower chamber was performed. Stained cells were photographed under an IX53 inverted microscope (Olympus, Tokyo, Japan), and the Image-Pro Plus software program (Media Cybernetics, Rockville, MD) was used to count the cells.

\section{Analysis of apoptosis via flow cytometry}

hep-2 cells transfected with siTUG1 or control siRNA for $48 \mathrm{~h}$ were completely trypsinized and resuspended at a concentration of $2 \times 10^{5}$ cells/ml. After staining with $5 \mu$ l of annexin V-fluorescein isothiocyanate and $10 \mu \mathrm{l}$ of propidium iodide (PI) using an FITC Annexin V Apoptosis Detection Kit (BD Biosciences), the percentage of apoptotic cells (annexin V+/PI- and annexin V+/PI+ cells) was determined using a BD FACSCalibur flow cytometer (BD Biosciences).

Cell-cycle assays

At $48 \mathrm{~h}$ after transfection with siTUG1 or control siRNA, Hep-2 cells were harvested, washed twice with cold phosphate-buffered saline, and fixed with ice-cold $70 \%$ ethanol for $24 \mathrm{~h}$ at $4{ }^{\circ} \mathrm{C}$. After centrifugation at 


\section{Cellular Physiology Cell Physiol Biochem 2018;49:2511-2520 \begin{tabular}{ll|l} 
and Biochemistry Published online: 28 September 2018 & $\begin{array}{l}\text { (c) } 2018 \text { The Author(s). Published by S. Karger AG, Basel } \\
\text { www.karger.com/cpb }\end{array}$ \\
\hline
\end{tabular} \\ Zhang et al.: The Role of Upregulated TUG1 in LSCC}

$1500 \mathrm{rpm}$ for $5 \mathrm{~min}$, the cells were washed twice with phosphate-buffered saline and resuspended with $0.5 \mathrm{ml}$ of phosphate-buffered saline containing PI $(50 \mu \mathrm{g} / \mathrm{ml})$ and RNase $(100 \mu \mathrm{g} / \mathrm{ml})$. The cells were then incubated in $37^{\circ} \mathrm{C}$ water in the dark for $30 \mathrm{~min}$, and the cell-cycle distribution was assessed using flow cytometry and the ModFit software program (version 3.0; BD Biosciences).

\section{Western blot analysis}

Total protein was obtained from Hep-2 cells using RIPA lysis buffer (Beyotime, Haimen, China) containing 1\% protease inhibitor cocktail (Sigma-Aldrich, St. Louis, MO). Decharged protein specimens were separated using sodium dodecyl sulfate-polyacrylamide gel electrophoresis and then electrotransferred onto a polyvinylidene fluoride membrane (Bio-Rad, Hercules, CA). After being blocked with 5\% nonfat milk at room temperature for $2 \mathrm{~h}$, the membrane was incubated with the indicated primary antibodies overnight at $4^{\circ} \mathrm{C}$. Enhanced chemiluminescence reagents (Merck Millipore, Darmstadt, Germany) were used for developing blots after the membrane was incubated with the corresponding secondary antibodies. The primary antibodies were used at the following dilutions: anti-p53, 1:1000 (Sigma, St. Louis, M0); antiGAPDH, 1:2000 (CloudSeq Biotech Inc., Shanghai, People's Republic of China). GAPDH was used as a loading control.

\section{Statistical analysis}

All experiments were repeated at least three times. Data were presented as the mean \pm standard deviation. The relationship of the patients' clinicopathological characteristics with TUG1 expression was analyzed using the chi-square test or Fisher exact test. The Mann-Whitney $U$ test or a paired $t$-test was used to assess differences between two experimental groups. The SPSS software program (version 22.0; IBM Corporation, Armonk, NY) was used for data analysis. $P$ values less than 0.05 were considered statistically significant.

\section{Results}

Elevated expression of TUG1 in LSCC

Our qRT-PCR analysis performed to measure the relative expression of TUG1 in 64 pairs of LSCC and corresponding adjacent nontumor tissue specimens demonstrated significantly higher expression of TUG1 in the LSCC specimens $(P<0.05)$ (Fig. 1). This suggested that TUG1 was involved in the pathogenesis of LSCC.

Correlation of TUG1 expression with the clinicopathological features of LSCC patients

To further investigate the relationship between TUG1 expression and clinicopathological characteristics, we placed the study patients in two groups according to median TUG1 expression level (high versus low). As shown in Table 1, high TUG1 expression was significantly correlated with advanced T category $(P=0.025)$, worse lymph node metastasis $(P=0.014)$, and late clinical stage $(P=$ 0.003 ). However, we did not find any significant correlations of TUG1 expression with other clinicopathological features, such as age, sex, and differentiation.

Inhibition of Hep-2 cell proliferation by TUG1 depletion in vitro

Furthermore, we observed that TUG1 influenced the biological behavior of Hep-2 cells in in vitro experiments. We used siTUG1 to disrupt

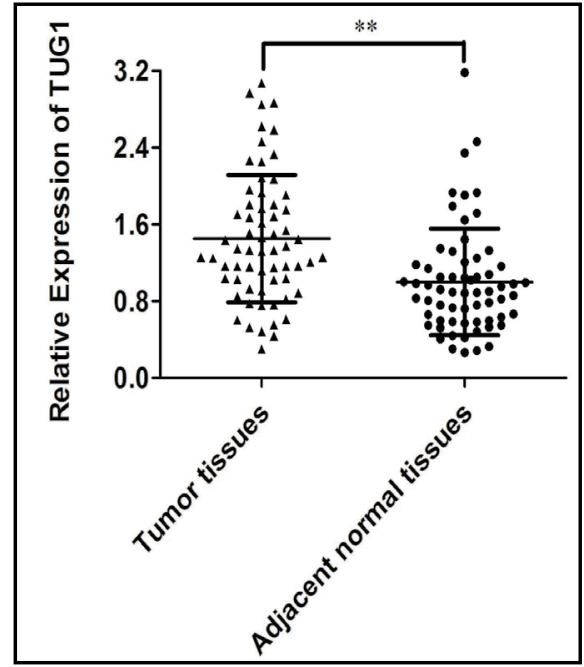

Fig. 1. Higher expression of TUG1 in LSCC specimens than in paired adjacent normal tissue specimens $(\mathrm{N}=64)$ identified in qRT-PCR assays. ${ }^{* *} \mathrm{P}<0.01$ (paired t-test). 
expression of TUG1 in Hep-2 cells. In comparison with that in Hep-2 cells transfected with the scrambled sequence (controls), the levels of TUG1 expression were markedly lower in cells transfected with siTUG1 (Fig.

2A).

Next, we performed MTT assays to assess the proliferation of Hep-2 cells after transfection with siTUG1. We observed that depletion of TUG1 in Hep-2 cells markedly inhibited their proliferation (Fig. 2B).

Contribution of TUG1 to LSCC metastasis via increasing the invasive and migratory ability of Hep-2 cells

Considering that TUG1 expression was significantly correlated with lymph node metastasis of LSCC, we used Transwell assays to further investigate whether TUG1 promotes metastasis of tumor cells. Knockdown of TUG1 expression in hep- 2 cells considerably attenuated their invasive and migratory ability (Fig. 3), suggesting that that TUG1 could enhance the invasive and migratory ability of LSCC cells. Thus, we proposed that TUG1 also functions as a prometastatic factor in LSCC cells.

Promotion of apoptosis and induction of cell-cycle arrest by TUG1 silencing in Hep- 2 cells

To investigate the ways in which
Table 1. The relationship of TUG1 expression with clinicopathological characteristics of the 64 LSCC patients

\begin{tabular}{|c|c|c|c|c|}
\hline \multirow{2}{*}{ Characteristic } & \multirow{2}{*}{ Sum } & & Relative TUG1 expression & \multirow{2}{*}{ P-value } \\
\hline & & Low & High & \\
\hline Age, years & & & & 0.265 \\
\hline$<60$ & 26 & 16 & 10 & \\
\hline$\geq 60$ & 38 & 18 & 20 & \\
\hline Sex & & & & 0.850 \\
\hline Male & 56 & 29 & 27 & \\
\hline Female & 8 & 5 & 3 & \\
\hline Smoking & & & & 0.280 \\
\hline Never & 5 & 1 & 4 & \\
\hline Ever & 59 & 33 & 26 & \\
\hline Alcohol & & & & 0.688 \\
\hline Never & 12 & 7 & 5 & \\
\hline Ever & 52 & 27 & 25 & \\
\hline Primary tumor location & & & & 0.226 \\
\hline Supraglottic & 29 & 13 & 16 & \\
\hline Glottic & 35 & 21 & 14 & \\
\hline Differentiation & & & & 0.092 \\
\hline Well or moderate & 47 & 22 & 25 & \\
\hline Poor & 17 & 12 & 5 & \\
\hline $\mathrm{T}$ category & & & & 0.025 \\
\hline T1-T2 & 45 & 28 & 17 & \\
\hline $\mathrm{T} 3-\mathrm{T} 4$ & 19 & 6 & 13 & \\
\hline Lymph node metastasis & & & & 0.014 \\
\hline Negative & 40 & 26 & 14 & \\
\hline Positive & 24 & 8 & 16 & \\
\hline Clinical stage & & & & 0.003 \\
\hline I-II & 36 & 25 & 11 & \\
\hline III-IV & 28 & 9 & 19 & \\
\hline
\end{tabular}

TUG1 affects LSCCcell proliferation, we used flow cytometry to observe its effects on apoptosis and division of hep-2 cells. The results revealed that transfection with siTUG1 markedly induced apoptosis in Hep-2 cells (Fig. 4A), indicating that TUG1 has an antiapoptotic role. Cell-cycle analysis revealed that, unlike

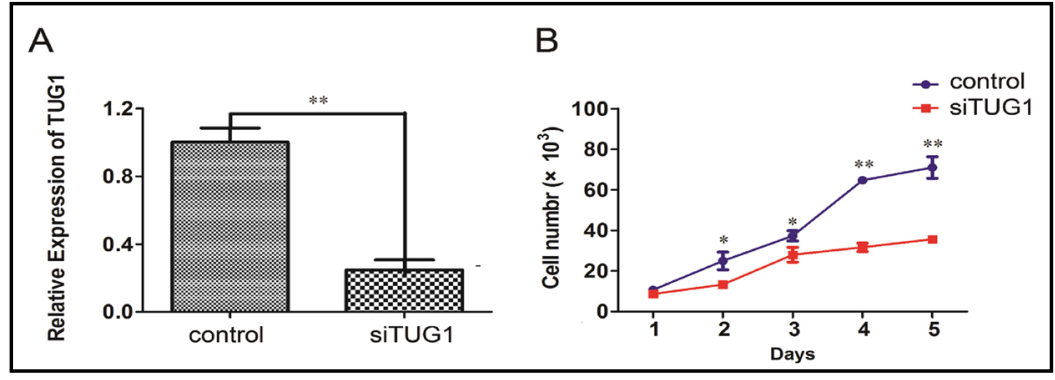

Fig. 2. Inhibition of Hep-2 cell proliferation by TUG1 depletion. (A) The silencing efficiency of siTUG1 as assessed using qRT-PCR assays $48 \mathrm{~h}$ after transfection of Hep-2 cells with a scrambled sequence (Control) or siTUG1 ( $\mathrm{N}=$ 3). ${ }^{* *} \mathrm{P}<0.01$ (Mann-Whitney U test). (B) The proliferation of transfected Hep-2 cells as determined using MTT assays. The absorbance at $570 \mathrm{~nm}$ in each well was measured on 5 consecutive days after cells were plated in triplicate. The cells in the two indicated groups were counted based on the standard growth curve $(\mathrm{N}=3) .{ }^{*} \mathrm{P}<0.05 ;{ }^{*} \mathrm{P}<0.01$ (Mann-Whitney $\mathrm{U}$ test). 
transfection with the scrambled sequence, siTUG1 reduced the number of cells in S phase (Fig. 4B).

Induction of increased p53 expression by TUG1 downregulation in Hep-2 cells

Next, we sought to determine whether TUG1 played a role in Hep-2 cells by affecting expression of p53, a well-known tumor suppressor whose expression is closely associated with the pathogenesis of head and neck squamous cell carcinoma. We found that TUG1 knockdown obviously increased the expression of p53 mRNA $(P=0.018)$ (Fig. 5A) as well as that of p53 protein $(P=0.003)$ (Fig. 5B), implying that TUG1 might partly function by negatively regulating the expression of $\mathrm{p} 53$.

\section{Discussion}

LSCC is one of the most malignant forms of the head and neck squamous cell carcinomas, and complicated biological and oncogenic processes are involved in its pathogenesis. Because of advances in diagnosis and treatment, the 5 -year survival rate in

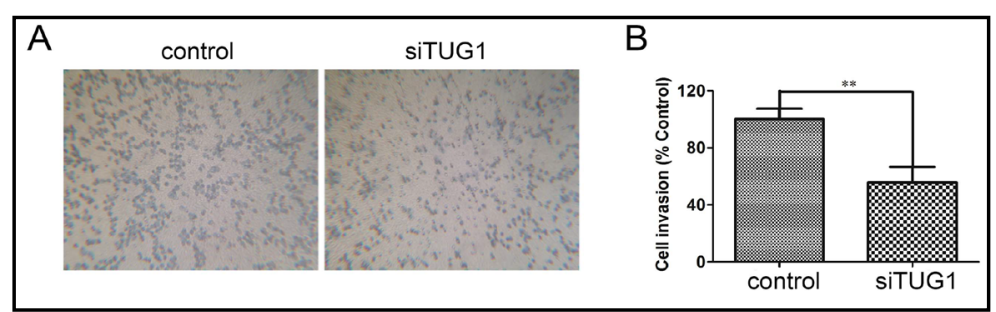

Fig. 3. Silencing of the TUG1-attenuated invasive and migratory properties of Hep-2 cells. Hep-2 cells transfected with siTUG1 or the scramble control were incubated in corresponding chambers following the manufacturer's instructions. After culture for $72 \mathrm{~h}$, (A) invasive and (B) migratory cells were stained with a $0.1 \%$ crystal violet solution and counted. Representative photomicrographs of all cells and quantitative results are shown $(\mathrm{N}=3) .{ }^{* *} \mathrm{P}<0.01$ (Mann-Whitney $\mathrm{U}$ test).

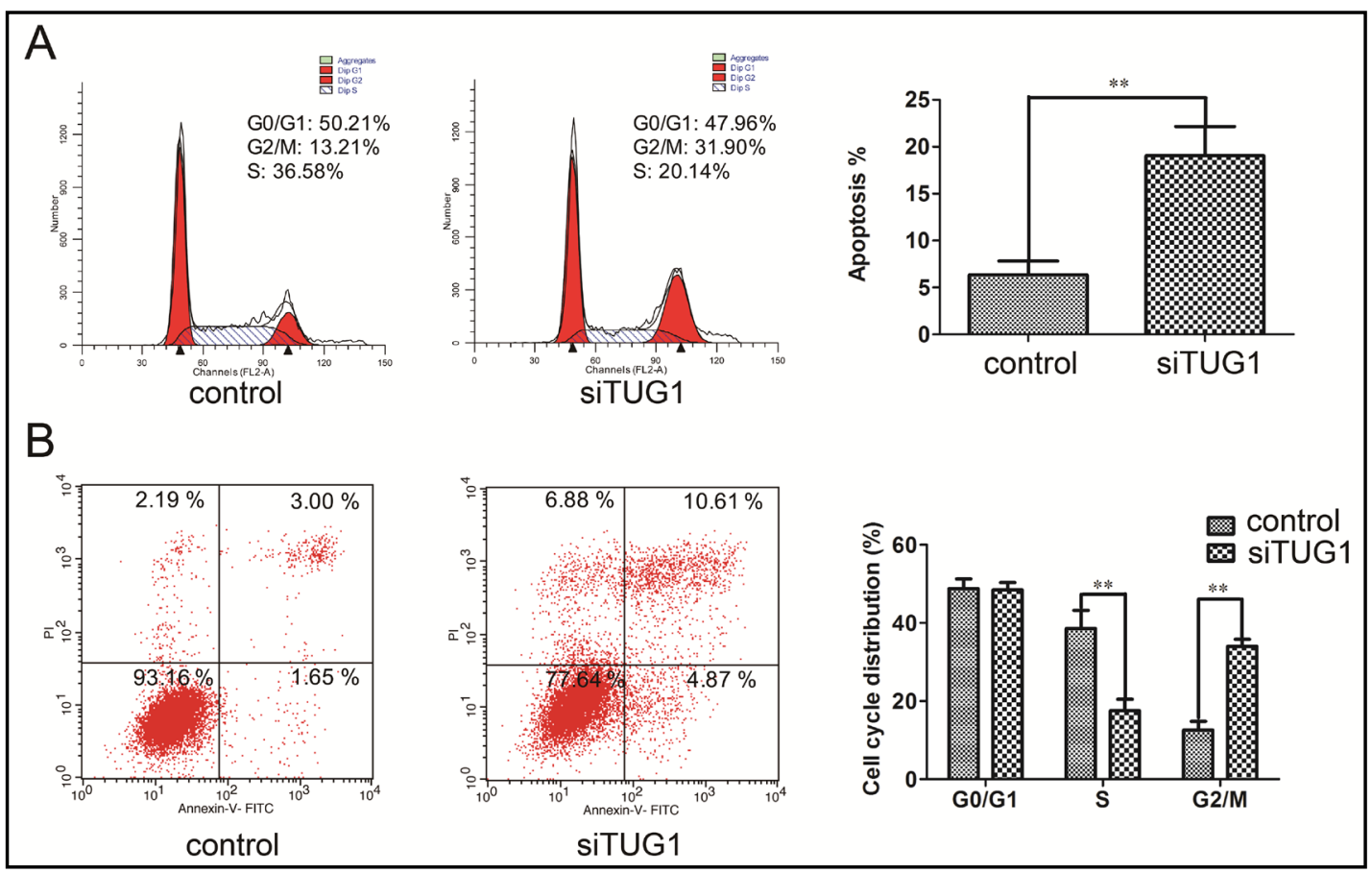

Fig. 4. Increased apoptosis and reduced numbers of S-phase cells due to TUG1 knockdown in Hep-2 cells. At $48 \mathrm{~h}$ after transfection with siTUG1 or the scramble control, (A) the percentages of apoptotic Hep-2 cells were determined using annexin V/PI dual staining assays, and (B) the cell-cycle distribution was determined using PI staining. Representative scatterplots and quantitative results are shown $(\mathrm{N}=3)$. ${ }^{* *} \mathrm{P}<0.01$ (MannWhitney U test). 
the United States for LSCC has improved from $59.6 \%$ to $66.8 \%$ over the past 30 years [23]. With the development of molecular biological technology and gene sequencing analyses, researchers found that several lncRNAs are promising biomarkers of LSCC [17-19].

Recently, several studies confirmed that the IncRNA TUG1 plays an important role in the development of several human cancers, such as non-small cell lung cancer [24],

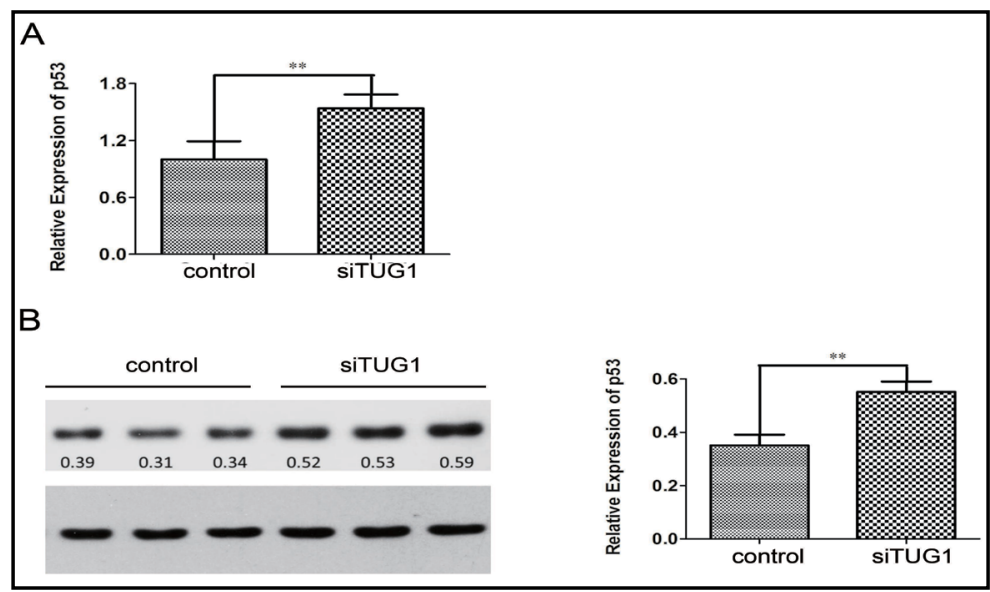

Fig. 5. Increased p53 expression in Hep-2 cells due to inhibition of TUG1 expression by siRNA. The relative expression of p53 (A) mRNA and (B) protein was measured using qRT-PCR or Western blot assays $48 \mathrm{~h}$ after Hep-2 cells were transfected with the scramble control or siTUG1 $(\mathrm{N}=3)$. ${ }^{* *} \mathrm{P}<0.01$ (Mann-Whitney U test). osteosarcoma [25],

hepatocellular carcinoma [26], esophageal squamous cell carcinoma [27], and colorectal cancer [28]. In the present study, we demonstrated that TUG1 expression was markedly higher in LSCC specimens than in adjacent normal tissue specimens, which was similar to most of the above-mentioned achievements. Moreover, our analysis revealed that high TUG1 expression was highly associated with advanced $\mathrm{T}$ category, late clinical stage, and worse lymph node metastasis in LSCC patients. Likewise, Zhang et al. [24] reported that TUG1 expression was downregulated in non-small cell lung cancer cells and that its expression was correlated with advanced pathological stage and increased tumor size. Also, Xu et al. [27] reported that TUG1 expression was upregulated in esophageal squamous cell carcinomas. Furthermore, TUG1 expression was related to tumor location, but not to age, tumor size, differentiation, TNM stage, or lymph node metastasis. The results of our study, in combination with those reported by other researchers, suggest that TUG1 acts as an oncogene in a variety of malignancies but likely in different ways.

Furthermore, we investigated the biological functions of TUG1 in Hep-2 cells in vitro via RNA interference-mediated knockdown. We found that TUG1 knockdown obviously suppressed the proliferation of Hep-2 cells, but induced apoptosis of the cells. Additionally, depletion of TUG1 caused cell-cycle arrest in Hep-2 cells. We thought that TUG1 might promote proliferation of Hep-2 cells via inhibition of apoptosis and acceleration of cell division and that this role of TUG1 might contribute to LSCC growth, which was consistent with our observations in patient specimens. In addition, silencing of TUG1 markedly reduced the migratory and invasive ability of Hep-2 cells, which explained why TUG1 was overexpressed in lymph node metastasis-positive LSCC specimens. Other research teams reported similar results over the past several years.

Despite these findings, the detailed molecular mechanisms of TUG1's activity in LSCC remain unclear. Recent studies revealed several mechanisms by which TUG1 executed functions in tumor cells, including some pathways and epithelial-mesenchymal transition. Wnt/ $\beta$-catenin signaling is an important signaling pathway in LSCC development by which some regulatory factors exert their functions $[29,30]$. Epithelial-mesenchymal transition is one of the most crucial steps in metastatic tumor progression and enhances cells' migratory and invasive properties [31]. In oral squamous cell carcinomas, elevated expression of TUG1 promoted tumor cell growth, proliferation, and invasion by suppressing Wnt/ $\beta$ catenin signaling [32]. Results of an investigation of cervical cancers suggested that TUG1 knockdown decreased the expression of epithelial-mesenchymal transition-related proteins 
[33]. Moreover, Liang et al. [34] reported that TUG1 could inhibit apoptosis and induce epithelial-mesenchymal transition via the Wnt/ $\beta$-catenin pathway in tumors. These studies provided us with a basis for the further study of the mechanism of TUG1's involvement in the pathogenesis of LSCC.

In addition, TUG1 may act via a p53-dependant pathway as evidenced by the fact that p53 is a well-known tumor suppressor in head and neck squamous cell carcinomas and our data demonstrating that downregulation of TUG1 expression by siRNA markedly increased p53 mRNA and protein expression in and attenuated the malignant characteristics of LSCC cells. However, other researchers proposed that TUG1 expression can be induced by p53 and binds to polycomb repressive complex 2, resulting in inhibition of the expression of specific genes involved in cell-cycle regulation [35]. Additionally, Zhang and colleagues discovered that TUG1 participated in the AKT/mitogen-activated protein kinase signaling pathway in non-small cell lung cancer cells by epigenetically regulating HOXB7 expression and that TUG1 was a direct transcriptional target of p53 [24]. We speculated that the difference between our results and others was due to the fact that tumors were histologically different and that the pathological processes involved in these tumors were quite complex. We tentatively thought that a reciprocal regulatory mechanism might underlie p53 and TUG1, which demands further investigation. Furthermore, investigators have identified several targets of TUG1, such as the microRNAs MiR-197 [36], MiR-221 [37], MiR-222 [37] and MiR382 [38] and Krüppel-like factor [26], and that the interaction between TUG1 and these targets may can cause transcriptional changes in downstream genes, expression of which is crucial for processes such as tumorigenesis and metastasis. Therefore, we plan to further investigate the molecular mechanism of TUG1's involvement in the pathogenesis of LSCC, including its impact on the p53-dependent signaling pathway, to fully understand its function.

In this study, we have profiled the role of TUG1 in the pathogenesis of LSCC. However, the molecular mechanism of TUG1 remains to be investigated. In the future, we prepare to search for the protein or miRNA target of TUG1 using RNA pull down technology or dual luciferase reporter system. Additionally, in vivo experiments will be conducted in order to confirm the role of TUG1, using mouse models we have established before [39].

\section{Conclusion}

In conclusion, we for the first time verified the clinical significance of TUG1 by demonstrating its overexpression in LSCCs and the relationship of its expression with the clinical features of LSCC patients. Our in vitro experiments further confirmed that upregulated TUG1 in LSCC might act as an oncogene by promoting the proliferation and invasive and migratory ability of LSCC cells. Taken together, these findings demonstrated that TUG1 would become a potential diagnostic biomarker or new therapeutic target for the management of LSCC.

\section{Abbreviations}

lncRNAs (long noncoding RNAs); TUG1 (taurine-upregulated gene 1); qRT-PCR (quantitative real-time polymerase chain reaction); LSCC (laryngeal squamous cell carcinoma); EGFR (epidermal growth factor receptor); PI (propidium iodide); Hep-2 (human epithelial-2); ECL (enhanced chemiluminescence); SD (standard deviation); PVDF (polyvinylidene fluoride); SDS-PAGE (sodium dodecyl sulfate-polyacrylamide gel). 


\section{Cellular Physiology Cell Physiol Biochem 2018;49:2511-2520

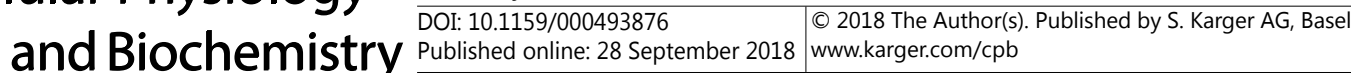 Zhang et al.: The Role of Upregulated TUG1 in LSCC}

\section{Acknowledgements}

This work was supported by the Taishan Scholars Program (No. tshw20130950), Shandong Province, and the Department of Science \& Technology of Shandong Province (No. ZR2013HM107, ZR2014HM005, 2015GSF118014 and 2015GSF118030), and Science Foundation of Qilu Hospital of Shandong University; and the Fundamental Research Funds of Shandong University (No.2014QLKY05).

\section{Disclosure Statement}

The authors declare no conflicts of interest.

\section{References}

1 Chen WQ, Zheng RS, Baade PD, Zhang SW, Zeng HM, Bray F, Jemal A, Yu XQ, He J: Cancer statistics in China, 2015. CA Cancer J Clin 2016;66:115-132.

-2 Zhang XW, He XG, Li XJ, Wang YL: Expression of EGFR about different region tissues and its relationship with histological differentiation in laryngeal carcinoma. Lin Chung Er Bi Yan Hou Tou Jing Wai Ke Za Zhi 2012;26:123-128.

-3 Lionello M, Lovato A, Staffieri A, Blandamura S, Turato C, Giacomelli L, Staffieri C, Marioni G: The EGFRmTOR pathway and laryngeal cancer angiogenesis. Eur Arch Otorhinolaryngol 2014;271:757-764.

4 Celenk F, Bayramoglu I, Yilmaz A, Menevse A, Bayazit Y: Expression of cyclooxygenase-2, 12-lipoxygenase, and inducible nitric oxide synthase in head and neck squamous cell carcinoma. J Craniofac Surg 2013;24:1114-1117.

5 Chen YF, Luo RZ, Li Y, Cui BK, Song M, Yang AK, Chen WK: High expression levels of COX-2 and P300 are associated with unfavorable survival in laryngeal squamous cell carcinoma. Eur Arch Otorhinolaryngol 2013;270:1009-1017.

-6 Karpathiou G, Monaya A, Forest F, Froudarakis M, Casteillo F, Marc Dumollard J, Prades JM, Peoc'h M: p16 and p53 expression status in head and neck squamous cell carcinoma: a correlation with histological, histoprognostic and clinical parameters. Pathology 2016;48:341-348.

7 Zhang YY, Xu ZN, Wang JX, Wei DM, Pan XL: G1/S-specific Cyclin-D1 might be a prognostic biomarker for patients with laryngeal squamous cell carcinoma. Asian Pac J Cancer Prev 2012;13:2133-2137. Yu X, Li Z: The role of microRNAs expression in laryngeal cancer. Oncotarget 2015;6:23297-23305. Derrien T, Johnson R, Bussotti G, Tanzer A, Djebali S, Tilgner H, Guernec G, Martin D, Merkel A, Knowles DG, Lagarde J, Veeravalli L, Ruan X, Ruan Y, Lassmann T, Carninci P, Brown JB, Lipovich L, Gonzalez JM, Thomas M, et al.: The GENCODE v7 catalog of human long noncoding RNAs: analysis of their gene structure, evolution, and expression. Genome Res 2012;22:1775-1789.

10 Mercer TR, Dinger ME, Mattick JS: Long non-coding RNAs: insights into functions. Nat Rev Genet 2009;10:155-159.

11 Arriaga-Canon C, Fonseca-Guzmán Y, Valdes-Quezada C, Arzate-Mejía R, Guerrero G, Recillas-Targa F: A long non-coding RNA promotes full activation of adult gene expression in the chicken alpha-globin domain. Epigenetics 2014;9:173-181.

-12 Peter S, Borkowska E, Drayton RM, Rakhit CP, Noon A, Chen W, Catto JW: Identification of differentially expressed long noncoding RNAs in bladder cancer. Clin Cancer Res 2014;20:5311-5321.

13 Prensner JR, Chinnaiyan AM. The emergence of IncRNAs in cancer biology: Cancer Discov 2011;1:391-407.

14 Spizzo R, Almeida MI, Colombatti A, Calin GA: Long non-coding RNAs and cancer: a new frontier of translational research? Oncogene 2012;31:4577-4587.

15 Gibb EA, Brown CJ, Lam WL: The functional role of long non-coding RNA in human carcinomas. Mol Cancer 2011;10:38.

16 Reis EM, Verjovski-Almeida S: Perspectives of Long Non-Coding RNAs in Cancer Diagnostics. Front Genet 2012;3:32.

17 Li DD, Feng JP, Wu TY, Wang YD, Sun YN, Ren JY, Liu M: Long intergenic noncoding RNA HOTAIR is overexpressed and regulates PTEN methylation in laryngeal squamous cell carcinoma. Am J Pathol 2013;182:64-70. 


\section{Cellular Physiology Cell Physiol Biochem 2018;49:2511-2520

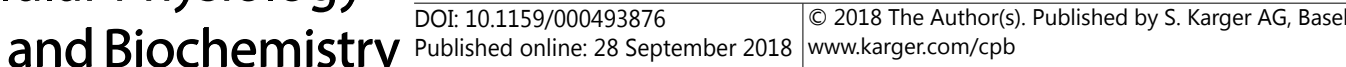 \\ Zhang et al.: The Role of Upregulated TUG1 in LSCC}

18 Feng J, Tian L, Sun Y, Li D, Wu T, Wang Y, Liu M: Expression of long non-coding ribonucleic acid metastasisassociated lung adenocarcinoma transcript-1 is correlated with progress and apoptosis of laryngeal squamous cell carcinoma. Head Neck Oncol 2012;4:46-52.

19 Wu TY, Qu LM, He GQ Tian LL, Li L, Zhou H, Jin Q, Ren JY, Wang Y, Wang JT, Kan X, Liu M, Shen J, Guo M, Sun YN: Regulation of laryngeal squamous cell cancer progression by the lncRNA H19/miR-148a-3p/DNMT1 axis. Oncotarget 2015;7:11553-11566.

20 Young TL, Matsuda T, Cepko CL: The noncoding RNA taurine upregulated gene 1 is required for differentiation of the murine retina. Curr Biol 2005;15:501-512.

21 Edge SB, Compton CC: The American Joint Committee on Cancer: the 7th edition of the AJCC cancer staging manual and the future of TNM. Ann Surg Oncol 2010;17:1471-1474.

-22 Livak KJ, Schmittgen TD: Analysis of relative gene expression data using real- time quantitative PCR and the 2(-Delta Delta C(T)) method. Methods, 2001;25:402-408.

23 Howlader N, Noone AM, Krapcho M, Garshell J, Miller D, Altekruse SF, Kosary CL, Yu M, Ruhl J, Tatalovich Z, Mariotto A, Lewis DR, Chen HS, Feuer EJ, Cronin KA: SEER Cancer Statistics Review, 1975-2013, National Cancer Institute. Bethesda, MD. URL: https://seer.cancer.cov/archive/csr/1975_2013.

$\checkmark 24$ Zhang EB, Yin DD, Sun M, Kong R, Liu XH, You LH, Han L, Xia R, Wang KM, Yang JS, De W, Shu YQ Wang ZX: P53-regulated long non-coding RNA TUG1 affects cell proliferation in human non-small cell lung cancer, partly through epigenetically regulating HOXB7 expression. Cell Death Dis 2014;5:e1243.

25 Li Z, Dou P, Liu T, He S: Application of long noncoding RNAs in osteosarcoma: biomarkers and therapeutic targets. Cell Physiol Biochem 2017;42:1407-1419.

-26 Huang MD, Chen WM, Qi FZ, Sun M, Xu TP, Ma P, Shu YQ: Long non-coding RNA TUG1 is up-regulated in hepatocellular carcinoma and promotes cell growth and apoptosis by epigenetically silencing of KLF2 Mol Cancer 2015;14:165-176.

-27 Xu YT, Wang J, Qiu,MT, Xu L, Li M, Jiang F, Yin R, Xu L: Upregulation of the long noncoding RNA TUG1 promotes proliferation and migration of esophageal squamous cell carcinoma. Tumour Biol 2014;36:16431651.

28 Wang L, Zhao ZX, Feng WD, Ye ZJ, Dai WG, Zhang CH, PengJJ, Wu KM: Long non-coding RNA TUG1 promotes colorectal cancer metastasis via EMT pathway. Oncotarget 2016;7:51713-51719.

29 Chen S, Sun YY, Zhang ZX, Li YH, Xu ZM, Fu WN: Transcriptional suppression of microRNA-27a contributes to laryngeal cancer differentiation via GSK-3 $\beta$-involved Wnt/ $\beta$-catenin pathway. Oncotarget 2017;8:1470814718.

-30 Yang N, Hui L, Wang Y, Yang HJ, Jiang XJ: Overexpression of SOX2 promotes migration, invasion, and epithelial-mesenchymal transition through the Wnt/ $\beta$-catenin pathway in laryngeal cancer Hep-2 cells. Tumour Biol 2014;35:7965-7973.

-31 Thiery JP, Acloque H, Huang RY, Nieto MA: Epithelial-mesenchymal transitions in development and disease. Cell 2009;139;871-890.

32 Liang S, Zhang SZ, Wang P, Yang C, Shang C, Yang JJ, Wang J: LncRNA TUG1 regulates the oral squamous cell carcinoma progression possibly via interacting with Wnt/ $\beta$-catenin signaling. Gene 2017;608:49-57.

-33 Hu YY, Sun XW, Mao CC, Guo GQ Ye SS, Xu JF, Zou RM, Chen J, Wang LD, Duan P, Xue XY: Upregulation of long noncoding RNA TUG1 promotes cervical cancer cell proliferation and migration. Cancer medline 2017;6:471-482.

-34 Liang J, Liang LZ, Ouyang KX, Li ZQ, Yi XP: MALAT1 induces tongue cancer cells' EMT and inhibits apoptosis through Wnt/ $\beta$-catenin signaling pathway. J Oral Pathol Med 2017;46:98-105.

-35 Khalil AM, Guttman M, Huarte M, Garber M, Raj A, Morales DR, Thomas K, Presser A, Bernstein BE, Oudenaarden AV, Regev A, Lander ES, Rinn JL: Many human large intergenic noncoding RNAs associate with chromatin-modifying complexes and affect gene expression. Proc Natl Acad Sci U S A 2009;106:11667-11672.

-36 Fiori ME, Barbini C, Haas TL, Marroncelli N, Patrizii M, Biffoni M, Maria RD: Antitumor effect of miR-197 targeting in p53 wild-type lung cancer. Cell Death Differ 2014;21:774-782.

-37 Ihle MA, Trautmann M, Kuenstlinger H, Huss S, Heydt C, Fassunke J, Wardelmann E, Bauer S, Schildhaus HU, Buettner R, Merkelbach-Bruse S: MiRNA-221 and miRNA-222 induce apoptosis via the KIT/AKT signaling pathway in gastrointestinal stromal tumors. Mol Oncol 2015;9:1421-1433.

-38 Zhao L, Sun H, Kong H, Chen Z, Chen B, Zhou M: The Lncrna-TUG1/EZH2 axis promotes pancreatic cancer cell proliferation, migration and EMT phenotype formation through sponging miR-382. Cell Physiol Biochem 2017;42:2145-2158.

-39 Zhao XG, Sun RJ, Yang XY, Liu DY, Lei DP, Jin T, Pan XL: Chloroquine-enhanced efficacy of cisplatin in the treatment of hypopharyngeal carcinoma in xenograft mice. PloS One 2015;10:e0126147. 